\title{
Reseña de Sentencias del Tribunal Supremo (Tercer y cuarto trimestres de 1993)
}

\author{
María del Rosario Alonso Ibáñez

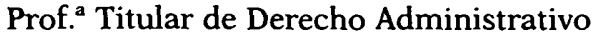 \\ Universidad de Oviedo
}

Sumario: I. ORGANIZACIÓN. II. EMPLEO PÚBLICO. III. HACIENDAS LOCALES. IV. JURISDICCION CONTENCIOSO-ADMINISTRATIVA. V. RESPONSABILIDAD PATRIMONIAL. VI. BIENES. VII. EXPROPIACIÓN FORZOSA. VIII. URBANISMO.

\section{ORGANIZACIÓN ADMINISTRATIVA}

1. Requerimiento del Delegado del Gobierno al Ayuntamiento de que éste le remitiera las Ordenanzas o Reglamentos que tuviera aprobados y vigentes con base en el art. 56 de la Ley 7/1985, de 2 de abril, Reguladora de las Bases del Régimen Local. Los Ayuntamientos no tienen la obligación de enviar sus Ordenanzas o Reglamentos al Estado, sino que es éste el que puede solicitar que se le exhiban los expedientes pero no que se le remitan. Alcance de las relaciones interadministrativas entre las distintas Administraciones territoriales.

«Invocándose en el requerimiento transcrito los arts. 56 y 65.2 de la Ley 7/1985, de 2 de abril, Reguladora de las Bases del Régimen Local, es preciso analizar su contenido para discernir si estos precepctos avalan aquel requerimiento.

El ap. 1 del art. 56 ciertamente que no ampara la mencionada exigencia que la autoridad del Estado dirige a la municipal, pues el mismo establece que las Entidades Locales tienen el deber de remitir a la Administración del Estado copia o, en su caso, extracto de los actos y acuerdos de las mismas, y como declaró la antigua Sala $4 .^{a}$ de este Tribunal en su Sentencia 15-4-1988, el indicado ap. 1 del art. 56 de la Ley impone solamente a las Corporaciones Locales la obligación de enviar a la Administración del Estado "copia o, en su caso, extracto comprensivo de los actos y acuerdos de aquellas", y no le obliga a remitirle otros documentos. 
El siguiente ap. 2 del art. 56 faculta en todo caso a la Administración del Estado a "recabar y obtener información completa sobre la actividad municipal, pudiendo solicitar incluso la exhibición de expedientes y la emisión de informes"; todo ello con el fin de comprobar la efectividad de la aplicación de la legislación estatal.

Resulta claro que la aludida facultad que ostenta la Administración del Estado de recabar y obtener información concreta sobre la actividad municipal y de solicitar incluso la exhibición de expedientes y la emisión de informes, tampoco amparaba la exigencia del Delegado del Gobierno de que el Ayuntamiento le remita todas las Ordenanzas y Reglamentos que la Corporación tuviere aprobados y vigentes; pues ésta no es la "información concreta sobre la actividad municipal" que el Estado puede exigir al Ayuntamiento según el repetido art. 56.2, ni tampoco es una solicitud del Estado de que se le exhiban expedientes o de que se le emitan informes, ya que una cosa es la solicitud de exhibición de expedientes y de emisión de informes, y otra distinta es exigir la remisión de todas las Ordenanzas y Reglamentos vigentes en el municipio. Los Ayuntamientos no tienen la obligación de enviar sus Ordenanzas o Reglamentos al Estado, sino que es éste el que puede solicitar que se le exhiban los expedientes, pero no que se le remitan; y el Estado tiene asimismo la facultad de pedir y de obtener información completa sobre la actividad municipal, pero no la de exigir que el Ayuntamiento le envíe todas sus Ordenanzas o Reglamentos.

Carece, pues, de acomodo en los examinados apartados del art. 56 de la Ley la exigencia remisoria; no siendo, por otro lado, tampoco de pertinente cita el art. 65.2 de la misma Ley, también aducido por el requerimiento del Delegado del Gobierno del Estado, dado que el Ayuntamiento no había adoptado ningún acuerdo que pudiera ser objeto del requerimiento anulatorio a que tal precepto se refiere.

El Capítulo II del Título V de la mencionada Ley Reguladora de las Bases del Régimen Local disciplina las relaciones interadministrativas para la debida efectividad de la coordinación y de la eficacia entre las Administraciones del Estado y de las Comunidades Autónomas, de un lado, y las Entidades Locales, de otro, debiendo unas y otras en sus relaciones recíprocas facilitar a las otras Administraciones la información sobre la propia gestión que sea relevante para el adecuado desarrollo por ellas de sus cometidos propios (art. 55. c) de dicha Ley); pero no entra tampoco en este apartado, que nadie invoca, legitimación para la tan repetida exigencia de la Delegación del Gobierno en Canarias de que el Ayuntamiento de La Oliva le remitiera todas las Ordenanzas o Regla- 
mentos vigentes de la Corporación municipal, pues la requirente, Administración del estado, para nada explica, ni menos justifica, el motivo o razón por el cual necesita la remisión de todas las disposiciones generales del municipio, ni tampoco acredita que esos Reglamentos u Ordenanzas hubieren de ser relevantes para el adecuado desarrollo de los cometidos del Estado, por lo que en estas circunstancias tampoco podía ser aplicable el art. 55. c) de la tan mencionada Ley de Bases; ya que no se puede olvidar que -como reconoce la Sentencia recurrida- el principio constitucional de autonomía de los entes locales proclamado en los arts. 137 y 140 de la Constitución, y el administrativo de la descentralización, impiden ejercer facultades de control sobre la actividad general de unos centros de poder sobre otros y, que, como explica la Exposición de Motivos de la Ley de Bases, las técnicas de relación entre Administraciones han de tener por objeto más bien la definición del marco y de los procedimientos que faciliten el encuentro y la comunicación, incluso informal, para la colaboración y coordinación interadministrativas fundamentalmente voluntarios y de base negocial. Pero que, naturalmente, el cuadro de técnicas ha de cerrarse por un sistema resolutorio del supuesto límite de conflicto, por fracaso de las mismas, debiendo configurarse ese sistema de resolución de conflictos de un modo respetuoso con la esencial igualdad posicional de las Administraciones Territoriales que a la vez asegure que el planteamiento y la sustanciación del conflicto no alteren la específica estructura constitucional de los intereses públicos a los que sirven dichas Administraciones. Pues la Ley, más que pretender garantizar la autonomía sobre la quietud de comportamientos estancos e incomunicados, y, en definitiva, sobre un equilibrio estático propio de las cosas inanimadas, busca fundamentar la autonomía en el equilibrio dinámico propio de un sistema de distribución del poder, tratando de articular los intereses del conjunto, reconociendo a cada uno lo suyo y estableciendo las competencias, principios, criterios y directrices que guíen la aplicación práctica de la norma en su conjunto de forma abierta a la realidad y a las necesidades del presente; pero habiéndose de tener siempre en cuenta en el ámbito de las relaciones interadministrativas que la actuación de una Administración respecto de la otra ha de moverse en todo momento en un plano de igualdad posicional y con la necesaria justificación del obrar de una Administración respecto de la otra, pues de otra manera se quebrarían aquellas bases de igualdad si se admitieran imposiciones que habrían de estimarse cuando menos injustificadas cuando no arbitrarias, que es precisamente lo que podría aquí predicarse de la expresada conducta de la Delegación del Gobierno respecto del Ayuntamiento al que sin darle motivo ni justificación de clase alguna de su pretensión, le exige la remisión incondicionada de todas las Ordenanzas 
o Reglamentos del municipio de los que evidentemente podía pedir información concreta justificando, o al menos explicando, un razonable motivo para su petición, tanto más cuanto que el Estado, lo mismo que los particulares, puede acceder directamente al contenido de las Ordenanzas o Reglamentos Municipales en virtud del principio de la publicidad de las normas garantizado constitucionalmente (art. 9.3 de la Constitución) y, en el ámbito local, concretado en el art. 70.2 de la propia Ley de Bases».

(Sentencia de 21 de septiembre de 1993. Ar. 6.537. Bruguera Manté.)

\section{EMPLEO PÚBLICO}

1. Acuerdo del Consejo de Gobierno de la Diputación General de Aragón, por el que se autorizó la tramitación del traslado de cinco Veterinarios Titulares destinados en otras Comunidades Autónomas para ocupar en destino provisional vacantes en el ámbito funcional específico del Departamento de Sanidad, Bienestar Social y Trabajo. El carácter provisional de los nombramientos no excluye que los mismos incurran en desviación de poder.

"Mediante el acuerdo impugnado la Diputación General de Aragón autoriza la realización de los trámites oportunos para asignar con carácter provisional a los cinco Veterinarios Titulares que en el mismo se mencionan, destinados en otras Comunidades Autónomas, las vacantes que se produzcan en la de Aragón, entendiendo la Sentencia apelada que tal decisión se enmarca en el ejercicio de la potestad de autoorganización de la Comunidad Autónoma, que "fases iniciales del desarrollo de su proceso autonómico y ante la falta de norma específica directa que venga a resolver las cuestiones que se suscitan, ha de acudir a tratamientos puntuales que solucionen - transitoriamente- determinadas situaciones que afecten a la Comunidad, con un grado de discrecionalidad que, dentro de los límites constitucionales y legales, no puede negarse al Gobierno Autónomo", rechazando, por consiguiente, las alegaciones impugnatorias de la parte actora y, entre ellas, la invocada desviación de poder.

Frente al criterio del Tribunal a quo, la Sala considera que el Acuerdo de la Diputación General de Aragón de 19-9-1989 ha incurrido en desviación de poder por cuanto que: a) Es manifiesta la intención de nombrar a los cinco Veterinarios Titulares que el propio acuerdo menciona, sin que conste previa convocatoria pública ni procedimiento selectivo 
JURISPRUDENCIA

alguno, careciendo, por otra parte, el expediente administrativo de antecedente o informe alguno que justifique la adopción de dicho acuerdo, evidenciándose así que se trata de designar a personas determinadas, sin que el carácter provisional de los nombramientos excluya que los mismos puedan incurrir en desviación de poder; b) La alegada ausencia de regulación específica en la materia no puede justificar el acto recurrido, toda vez, que en primer lugar, los arts. 19 y 31 de la Ley $1 / 1986$, de 20 de febrero, de Ordenación de la Función Pública de la Comunidad Autónoma de Aragón, permitían la convocatoria del oportuno concurso, pues si bien el art. 2.3 de dicha Ley autoriza a la Administración Autónoma a dictar normas específicas para, en su aplicación, adecuarla a las peculiaridades, entre otras, del personal sanitario, ello constituye una facultad cuyo ejercicio no puede entenderse que condicione, sin más, la aplicación de la mencionada norma legal a dicho personal, sin olvidar, por otro lado, el carácter supletorio del Decreto Autonómico 70/1987, de 9 de junio, por el que se aprueba el Reglamento de provisión de puestos de trabajo, conforme a lo dispuesto en su art. 1, en el que además, se impone, en todo caso, la obligatoriedad de la convocatoria pública. Por otra parte, difícilmente puede encontrar justificación el acto recurrido en la ausencia de regulación específica, cuando tal ausencia se subsanaba a los dos meses escasos con el Decreto 134/1989, de 14 de noviembre, y se trataba de asignar vacantes que no se habían producido.

Por consiguiente, ni el escueto expediente administrativo, que carece de todo antecedente acerca del acuerdo impugnado, ni las actuaciones practicadas, permiten apreciar que la finalidad realmente perseguida haya sido la satisfacción del interés público, resultando, en cambio, patente que se trataba de incorporar a la Administración de la Comunidad Autónoma a cinco funcionarios individualmente determinados, aunque fuera con carácter provisional, pues no debe olvidarse que la representación de la Administración no ha negado la alegación de la parte apelante relativa a que en el subsiguiente concurso, en el que se asignó puesto de trabajo con carácter definitivo a dichos funcionarios, se excluyó a los de otras Comunidades Autónomas».

(Sentencia de 26 de julio de 1993. Ar. 5.662. Lescure Martín).

2. Negociación colectiva en el ámbito funcionarial. Acuerdo del Pleno del Ayuntamiento aprobatorio del convenio colectivo afectante a los funcionarios y personal laboral fijo de dicho Ayuntamiento. Impugnación por la Administración del Estado. Actuación municipal que deroga normas imperativas e invade competencias legislativas por la 
vía del convenio pues la normativa estatutaria de los funcionarios públicos no puede ser promulgada de nuevo por una Corporación Local. Convenio suscrito bajo la vigencia de la Ley 9/1987, de 12 de junio, que se declara nulo.

«El debate contradictorio acerca de la validez de las cláusulas cuestionadas del convenio colectivo analizado ha sido planteado y resuelto en la instancia ponderando el juego de dos dimensiones interrelacionadas: la autonomía negociadora de las partes del convenio y la reserva de ley, aplicado a la relación estatutaria de los funcionarios públicos. La contradicción, pues, se plantea en torno a la existencia o no de extralimitación en el contenido de las cláusulas pactadas, teniendo en cuenta las fronteras impuestas por la Ley a esta modalidad de negociación colectiva.

Sin embargo, la peculiaridad de un pacto aplicable globalmente a un colectivo que está sujeto a ambos ordenamientos sustantivos netamente diferenciados, sugiere la previa interrogación acerca de la normalidad jurídica de este fenómeno, a cuya contestación se halla también vinculada la conclusión sobre la validez de lo pactado. En este sentido, advirtiendo que dicho extremo no había sido tomado en consideración por las partes como fundamento de sus respectivas pretensiones, entendimos que era procedente abrir un período de audiencia, de conformidad con el art. 43.2 de la Ley de la Jurisdicción, a dichos efectos. El hecho del transcurso del plazo concedido, sin que por ninguna de las partes se hayan formulado alegaciones acerca del extremo cuestionado en la audiencia, no excluye que abordemos su análisis y saquemos las pertinentes conclusiones, en conexión con lo pedido por los intervinientes en el proceso.

En resoluciones precedentes (v. gr. SSTS. 3..7, de 17 y 22 de marzo de 1993), en las que se discutía la validez de convenios unitarios para funcionarios y personal laboral suscritos con anterioridad a la vigencia de la Ley 9/1987, de 12 de junio, hemos declarado su nulidad fundados en el carácter estatutario de la relación funcionarial y en la falta de regulación en este ámbito de la negociación colectiva. Ahora bien, en el supuesto en que aquí se plantea el convenio combatido fue suscrito bajo la vigencia de la ley citada, la cual sirve de cobertura dialéctica de los argumentos esgrimidos en el debate de defensa de las respectivas posiciones. En consecuencia, lo que debe ahora dilucidarse consiste en determinar si los respectivos ordenamientos de la negociación colectiva (el de las relaciones estatutarias de los funcionarios públicos y el de las relaciones laborales de los trabajadores) ofrecen entre sí el grado de per- 
JURISPRUDENCIA

meabilidad suficiente para posibilitar una negociación y eventual regulación unitaria bajo forma contractual, y para ello, deben ponerse en relación los componentes básicos de los respectivos sistemas.

Siguiendo el orden de los factores, anteriormente enumerados, corresponde hacer aquí las siguientes precisiones: a) la estructura orgánica representativa integrada en la Mesa de Negociación, a que se refiere el art. 31.2 de la Ley 9/1987, no es coincidente con la prevista en el art. 87.1 de la Ley 8/1980 para la constitución de la Comisión Negociadora; b) el grado de autonomía de la negociación colectiva de los funcionarios, resultante de los arts. 32 y 35 de la Ley 9/1987, es manifiestamente más limitado que el reconocido a los trabajadores en el art. 85, de la Ley $8 / 1980$; c) la situación de supremacía de una de las partes, reflejada en el art. 35 de la Ley $9 / 1987$-al requerir la validez y eficacia de los pactos y acuerdos negociados la aprobación expresa y formal del Pleno de la Entidad local respectiva-, no tiene correlación en la letra de los arts. 82 y 90.2 de la Ley $8 / 1980$, aplicables inclusive cuando el empresario sea la Entidad pública; d) la misma diferencia de régimen jurídico se observa -en el supuesto de fracaso de la negociación-, entre lo establecido en el art. 37.2 de la Ley $9 / 1987$ y la regulación que deriva del Título II del RD Ley 17/1977, de 4 de marzo, y la STC 11/1981, de 8 abril; e) igualmente es notoria la diferencia en las reclamaciones jurisdiccionales relativas a esta materia, reservadas al orden contencioso-administrativo tratándose de funcionarios (arts. 9.4 y 24 LOPJ), en tanto es competencia del orden social cuando conciernen al personal laboral, sea pública o privada la unidad empleadora (arts. 9.5 y 25 LOPJ).

La trascendencia de las citadas contradicciones pone de manifiesto la inviabilidad de una articulación unitaria del pacto que abarque conjuntamente a los funcionarios y al personal laboral, cuyo primer escollo, como hemos dicho, se manifiesta en la dualidad de instancias jurisdiccionales en concurrencia. Procede, por tanto, la declaración de nulidad de conformidad con los arts. 47.1 c) y 47.2 de la Ley de Procedimiento Administrativo, aunque por razones de obligada congruencia con las pretensiones mantenidas en el proceso, esta declaración de nulidad debe limitarse estrictamente en cuanto a su alcance a las estipulaciones que el Abogado del Estado impugnó en el escrito de demanda y están especificadas en el FD1 de esta Sentencia y sin extenderse a los actos firmes y efectos agotados como consecuencia de la aplicación de las cláusulas anuladas.

La anulación de la totalidad de las estipulaciones cuestionadas, de acuerdo con las motivaciones anteriormente razonadas, nos releva de 
abordar el análisis y enjuiciamiento de los fundamentos de la Sentencia, ya sean referidos a los motivos de nulidad invocados por la Administración demandante o a las alegaciones de contrario, sostenidas por el Ayuntamiento demandado. Solamente nos resta puntualizar, por su conexión con los motivos de nulidad que hemos apreciado en esta Sentencia que, en términos de lege data, no es posible aceptar como ámbito de la autonomía contractual la tesis de asimilación analógica, postulada por el Ayuntamiento apelante ("parece ser la interpretación adecuada que el ámbito de la negociación empieza donde acaba la reserva de ley, que así opera como mínimo de derecho necesario, al igual que en el ámbito laboral, al que acudir obligadamente por analogía..."); ni siquiera la competencia residual que se reclama en la Sentencia: ("... la regulación de la función pública a través del Estatuto (...) no tiene por qué ser exhaustiva, y el propio Estatuto puede dejar un espacio sin cubrir, como en el ámbito laboral; remitiendo su determinación a la negociación entre las partes..."). La enumeración de las materias incluidas y vedadas a la negociación colectiva funcionarial, contenidas respectivamente en los arts. 32 y 36.2 de la Ley $9 / 1987$, no sólo hacen sustancialmente más restrictiva su regulación que la resultante de los arts. 82 y 85 de la Ley 8/1980 para los actores laborales, sino que tiene, también, el referente insoslayable de que los acuerdos versarán sobre materias competencia del Consejo de Ministros, Consejos de Gobierno de las Comunidades Autónomas o Pleno de las Entidades Locales (art. 35 Ley 9/1987); precepto que, a su vez, guarda relación con el art. 36.2 de la misma Ley facultando al órgano de gobierno de la Administración Pública correspondiente para establecer las condiciones de trabajo de los funcionarios públicos en los casos en que no se produzca acuerdo. El marco de contractualidad, por tanto, está en correlación con el contenido de las potestades normativas y de autoorganización del órgano administrativo correspondiente $y$, por otra parte, las características de pormenorización, rigidez y uniformidad inherentes al régimen estatutario emanado de la legislación básica del Estado y, en su caso, de los órganos legislativos de las Comunidades Autónomas, no permiten que por analogía con el sistema de relaciones laborales - tesis defendida por el Ayuntamiento apelante y en cierta medida aceptada por la Sentencia-, tal bloque legislativo sea identificable como plataforma de "mínimos", sobre la que pueda pivotar una constelación de unidades negociadoras pactando cada una a su libre albedrío, bajo el lema de que lo que no está prohibido por la ley debe presumirse que está permitido y puede ser objeto de regulación con arreglo al buen criterio de la Mesa de Negociación, refrendado por la respectiva Corporación Municipal».

(Sentencia de 22 de octubre de 1993. Ar. 7.544. García Carrero). 
JURISPRUDENCLA

\section{HACIENDAS LOCALES}

1. Impuesto municipal sobre el incremento del valor de los terrenos. Incidencia del cambio en la clasificación de la calle hecha por el Ayuntamiento sobre la fijación del valor inicial del inmueble. Recurso extraordinario de revisión.

"Tienen su origen estos autos en la impugnación, precisamente por el cauce excepcional del recurso de revisión, de la Sentencia de la Sala de lo Contencioso-Administrativo del Tribunal Superior de Justicia de Andalucía, con sede en Sevilla, de 19-11-1990, siendo ya de advertir que el motivo invocado es el del art. 102.1.b) de la Ley Jurisdiccional en redacción anterior a la Ley 10/1992, de 30 de abril.

Y ya con este punto de partida, para plantear la cuestión litigiosa será de recordar que la base imponible en el Impuesto Municipal sobre el Incremento del Valor de los Terrenos, en lo que a estos autos se refiere, "será la diferencia entre el valor corriente en venta del terreno al comenzar y al terminar el período de imposición" -art. 355.1 del Texto Refundido de las Disposiciones Legales Vigentes en materia de Régimen Local aprobado por el Real Decreto Legislativo 781/1986, de 18 de abril.

Y dado que entre ambos momentos puede producirse una alteración de circunstancias que puede provocar un cambio en la clasificación de la calle hecha por el Ayuntamiento en las fijaciones de los tipos unitarios de los valores corrientes en venta, es claro que este cambio ha de reflejarse en el valor final del terreno.

Sobre esta base, el tema discutido es el de si tal nueva clasificación ha de proyectarse también sobre la fijación del valor inicial.

La Sentencia impugnada da una respuesta afirmativa a esta cuestión en tanto que la citada como contradictoria - la del Tribunal Supremo de 22-1-1990 ha llegado a la solución opuesta.

Y concurriendo las identidades exigidas por el art. 102.1.b) de la Ley Jurisdiccional, necesaria será la fijación de la doctrina correcta.

El Tribunal Supremo tanto en la mencionada Sentencia como en otras posteriores -SS. 29 de enero y 10 de diciembre- viene entendiendo que aquella alteración de la clasificación de la calle no puede tener transcendencia para la fijación del valor inicial. 
Y esta es la doctrina que se estima ajustada al ordenamiento jurídico:

A) La estructura de este tributo implica la consideración de dos valores distintos, distintos precisamente porque refiriéndose a un mismo objetivo reflejan su valor corriente en venta en dos momentos diferentes. Es claro que para fijarlos habrá que atender a las circunstancias concurrentes en cada uno de esos momentos reflejadas, en lo que ahora importa, en una distinta clasificación de la calle.

La valoración inicial, en consecuencia, ha de determinarse con referencia a los datos del comienzo del período impositivo:

B) La fijación periódica de los tipos unitarios del valor corriente en venta hecha por los Ayuntamientos goza de la presunción de legalidad que caracteriza a las decisiones de la Administración - art. 8 de la Ley General Tributaria en relación con el art. 4.1.e) de la Ley 7/1985, Reguladora de las Bases del Régimen Local-, de suerte que no existan las estimaciones periódicas del Ayuntamiento para la fecha de iniciación del período impositivo habrá que atender a las “...valoraciones oficiales practicadas en aquella época" - art 355.3 del ya citado Texto Refundido- lo que corrobora la improcedencia de tener en cuenta acontecimientos posteriores al comienzo del período impositivo para fijar el valor inicial, con la salvedad que ahora se indicará.

C) La finalidad de este tributo es la de provocar una participación de la comunidad en los aumentos de valor de los terrenos producidos por causas independientes de la voluntad del propietario, por lo que el valor inicial sólo podrá alterarse, incrementándolo —reduciendo por tanto la base imponible-, cuando aquél haya introducido mejoras o cuando se hayan devengado contribuciones especiales - art. 355.4 del ya señalado Texto Refundido-.

En definitiva, cuando el dinamismo de la ciudad ha determinado una modificación en las circunstancias de una calle que dé lugar a un cambio en su clasificación, este dato nuevo posterior al comienzo del período impositivo, tendrá relevancia para la fijación del valor final, pero no afectará al valor inicial salvo que se acredite que el fijado en los tipos unitarios adolece de error y que, por tanto, no refleja el valor corriente en venta del terreno en ese momento inicial, lo que desde luego no ocurre en el caso que ahora se examina.

Ya en este punto será de recordar que el principio de efectividad de la tutela judicial - art. 24 de la Constitución-opera plenamente den- 
JURISPRUDENCIA

tro de los cauces que la legalidad ordinaria abre al recurso de revisión y, así las cosas, en los supuestos casacionales como es el del art. 102.1.b) de la Ley jurisdiccional —contradicción de Sentencias-aquel principio reclama, una vez apreciada esta contradicción, que el Tribunal Supremo no se limite a la rescisión del fallo impugnado remitiendo los autos a la Sala sentenciadora para la nueva Sentencia, sino que en aras a claras razones de economía procesal, exige que se dicte ya el pronunciamiento de fondo que resulte ajustado a Derecho, haciendo así innecesario el juicio rescisorio.

Procedente será, por consecuencia la rescisión de la Sentencia impugnada y al propio tiempo la desestimación del recurso contencioso-administrativo en que recayó".

(Sentencia de 14 de octubre de 1993. Ar. 7.939. Delgado Barrio).

\section{JURISDICCIÓN CONTENCIOSO-ADMINISTRATIVA}

1. Recurso de casación en interés de la ley. Legitimación de Ayuntamiento para recurrir contra las liquidaciones giradas por tributo local con efectos económicos desfavorables para el mismo. Falta de justificación del requisito de ser una Sentencia gravemente dañosa para el interés general.

«Hay que precisar, en primer lugar, que el Ayuntamiento de Granada está legitimado para interponer este recurso de casación en interés de la Ley. Así resulta de la naturaleza del interés general implicado en el proceso resuelto por el Tribunal Superior de Justicia de Andalucía y del alcance de la norma jurídica contenida en el enunciado del art. 102.b. párr.1 de la Ley Reguladora de esta Jurisdicción.

A tal efecto, hay que tener en cuenta que la reforma procesal operada en este Orden Jurisdiccional por la Ley 10/1992, de 30 de abril, ha venido a romper con el monopolio que el antiguo art. 101 de aquélla reconocía a la Abogacía del Estado - "aunque no hubiera intervenido en el procedimiento", rezaba este precepto- para acudir al recurso extraordinario de apelación en interés de la ley, antecedente inmediato del que aquí nos ocupa.

La Ley de Medidas Urgentes de Reforma Procesal deja abierto el recurso de casación en interés de la ley al Abogado del Estado, ya sin apostilla alguna, pero al propio tiempo permite que se pueda interponer 
también, a tenor del art. 102. párr. 1, de la Ley de esta Jurisdicción, en su nueva redacción, por las "Entidades o Corporaciones que ostenten la representación y defensa de intereses de carácter general o corporativo y tuviesen interés legítimo en el asunto", norma esta que, interpretada a la luz de la Exposición de Motivos de la Ley 10/1992 y del derecho fundamental reconocido en el art. 24. 1 de la Constitución en orden a la obtención de la tutela judicial efectiva, permite afirmar, sin violentar su texto, que la legitimación activa para interponer recurso excepcional viene referida tanto a las denominadas, por un sector de la doctrina, Corporaciones sectoriales de base privada (Colegios profesionales, Cámaras de Comercio, Industria y Navegación, etc.), como a las Entidades públicas, en general, a salvo la excepción derivada de la prevista en el párr. 2 del art. 102.b, siempre que unas y otras ostenten la representación y defensa, o lo que es igual, la gestión, del interés general comprometido por la doctrina propugnada en la Sentencia recurrida, ya que entonces únicamente tales "Entidades o Corporaciones" podrán tener "interés legítimo en el asunto", en palabras del legislador.

Por consiguiente, si el Municipio de Granada es una entidad pública, concretamente una entidad local de carácter territorial, si a su Ayuntamiento corresponde el "gobierno y administración municipal" - art. 19, párr. 1 de la Ley $7 / 1985$, de 2 de abril-que es tanto como decir la representación y defensa de los intereses generales de la comunidad vecinal, y si además la Sentencia impugnada se ha pronunciado sobre la justeza de unas liquidaciones giradas por un tributo local, el Impuesto Municipal de Radicación, con efectos económicos desfavorables para el Ayuntamiento de Granada, la conclusión, sobre este punto, no puede ser otra que la ya adelantada más arriba.

Precisada, pues, la legitimación activa de la Corporación municipal recurrente, hay que detenerse en otro punto que singulariza al recurso de casación en interés de la ley en este orden jurisdiccional respecto a su homónimo en el orden civil, por la trascendencia que tiene, como se verá, en su decisión.

El recurso diseñado en el art. 102.b de la Ley de esta jurisdicción no en un recurso en interés de la ley puro, esto es, concebido únicamente en defensa de ésta (de la ley en sentido formal y en sentido material, en este orden jurisdiccional), sino un medio de impugnación, a los solos efectos de formar jurisprudencia, en el que el legislador ha querido conjugar la defensa del ordenamiento jurídico con la del interés general implicado en el proceso, con el propósito de poner coto a doctrinas erróneas que si llegaran a consolidarse podrían generar, en su caso, un grave quebranto de dicho interés. 
JURISPRUDENCIA

Quiérese decir que en un recurso de esta naturaleza lo primero que hay que preguntarse es si la resolución impugnada, tachada de errónea, es en realidad "gravemente dañosa para el interés general", como expresamente exige el art. 102.b, párr. 1, ya que si la respuesta a este interrogante es negativa, huelga el análisis del acierto del fallo puesto en entredicho.

Pues bien, en el caso que se nos plantea el Ayuntamiento de Granada se limita en su recurso a afirmar, apodícticamente, que estima gravemente dañosa para el interés general - y errónea- la resolución dictada por el Tribunal a quo, sin desvelar las razones en que se apoya para hacer esa afirmación, a pesar de que corría a su cargo dar una explicación convincente al respecto. Esto es bastante para desestimar el recurso, pues el silencio de la Administración recurrente en punto tan fundamental de la mecánica del recurso de casación en interés de la ley nos impide conocer la importancia del detrimento económico que para las arcas municipales puede suponer la consolidación de una solución judicial pretendidamente errónea, cuyo círculo de destinatarios, por otro lado, no parece pueda ser numeroso, por venir referido exclusivamente a las Cajas de Ahorro con oficina abierta en el término municipal de Granada. Tampoco se puede desdeñar que los efectos económicos desfavorables para la Corporación exactora tienen, en cualquier hipótesis, un límite temporal máximo, 31-12-1994, establecido por la Disp. transit. tercera, párr. 2 de la Ley 39/1988, de 28 de diciembre, de Haciendas Locales -en la nueva redacción dada por el Real Decreto Ley 4/1990, de 28 septiembre-, y por la Ley 6/1991, de 11 marzo, para continuar en el disfrute de cualquier beneficio fiscal en la Licencia Fiscal de Actividades Comerciales e Industriales».

(Sentencia de 19 de octubre de 1993. Ar. 7.638. Rodríguez García).

\section{RESPONSABILIDAD PATRIMONIAL}

1. Reclamación de daños y perjuicios ante la Diputación Provincial por la imposibilidad de celebración de exposición de pintura en centro cultural adscrito a una Institución cultural sobre la que la citada Diputación ejerce patronazgo. Relación de causa-efecto. Existencia de daño moral indemnizable. Improcedencia de indemnización por lucro cesante.

"Alega la representación procesal de la Administración apelante, como primer motivo de impugnación de la Sentencia apelada, que el 
demandante, ahora apelado, debió, en su caso, dirigir su reclamación frente a la Institución Cultural "El Brocense", que goza de personalidad jurídica independiente y patrimonio propio, al estar, según el art. 2 de sus Estatutos, el Complejo Cultural "Santa María" de Plasencia (donde se hubiera celebrado la exposición de la obra pictórica del demandante) adscrito a dicha Institución.

Tal cuestión fue objeto de análisis por el Tribunal de instancia, que, a la vista de las pruebas practicadas (declaraciones del Diputado Provincial Delegado de Cultura y de otra Diputada Provincial), llegó a la conclusión de que fue la Administración demandada, ahora apelante, la que autorizó la celebración de la mentada exposición de la obra pictórica del demandante en el indicado Complejo Cultural "Santa María" de Plasencia, por lo que rechazó la aducida falta de legitimación pasiva.

En esta segunda instancia, la representación procesal de la Diputación Provincial apelante reitera la falta de legitimación pasiva de ésta y sostiene que lo único acreditado con la prueba practicada es que el pintor demandante realizó algunas gestiones, a título personal, con Diputados Provinciales para que se le concediera el uso de la sala destinada a exposiciones, en Plasencia, y que tales personas prometieron recomendar positivamente sus pretensiones.

Al parecer, tan eficaces fueron las recomendaciones de tales Diputados Provinciales que, aunque la Sentencia de instancia lo omite, se editó un cartel por la Diputación Provincial de Cáceres anunciando la exposición, según el cual había de celebrarse del 19-12-1987 al 30-1-1988 y por la Editora Regional de Extremadura un catálogo de dicha obra (documentos a los folios 35 a 92, 96, 97 y 174 de los autos), hechos probados éstos que abundan en la tesis sostenida por la Sala de instancia sobre participación de la Diputación Provincial en el anuncio y organización de la exposición aludida.

La Administración apelante, a pesar de que, contrariamente a lo dispuesto concordadamente por los arts. 94.3 de la Ley de Procedimiento Administrativo de 1958 y 38.2 de la Ley de esta Jurisdicción, guardó silencio respecto de la reclamación de daños y perjuicios formulada por el pintor demandante (quien denunció oportunamente la demora), no se recata en alegar en vía jurisdiccional que tal reclamación debió dirigirla aquél contra una Institución Cultural sobre la que la propia Administración demandada, ahora recurrente, ejerce patronazgo, según el art. 1 de los Estatutos de ésta (documento al folio 182 de los autos). Pues bien, tanto de las pruebas practicadas como de la desestimación pre- 
JURISPRUDENCLA

sunta de dicha reclamación, se deduce que fue la Diputación Provincial quien asumió la organización de la mentada exposición de la obra pictórica del demandante, pues, de lo contrario, hubiera remitido solicitud de éste a la Institución Cultural mencionada, dado que su Presidente nato es el propio Presidente de la Diputación Provincial y los miembros de su Junta Rectora son Diputados Provinciales (arts. 6 y 8 de los Estatutos de la Institución Cultural "El Brocense"). No es legítimo dar la callada por respuesta para reservarse la alegación de "falta de legitimación pasiva" al contestar la demanda, de manera que el silencio administrativo sólo puede interpretarse como desestimación de la pretensión de fondo formulada en su día en relación con los perjuicios causados por no haberse celebrado la proyectada exposición, lo que obliga, como acertadamente hizo la Sala de instancia, a rechazar tal motivo de inadmisibilidad.

El segundo motivo en el que basa su recurso de apelación la Diputación Provincial de Cáceres se concreta en la "falta de causa-efecto en cuanto a la pretensión del demandante", si bien al desarrollarlo, reitera la alegación anterior, afirmando que ni hubo solicitud para llevar a cabo la exposición de pintura ni compromiso para realizarla, hasta sostener que se trata de una "pura fabulación".

Estas afirmaciones deben rechazarse por las mismas razones anteriormente expuestas, ya que se ha acreditado que la Diputación Provincial había asumido el compromiso de realizar la exposición de la obra pictórica del demandante, la cual no se celebró por no encontrarse, en las fechas proyectadas para ello, acondicionada la sala en que debería haberse celebrado, de manera que la causa determinante de que aquélla no se llevase a cabo es imputable exclusivamente a un anormal funcionamiento del servicio público, al estar remodelando la sala correspondiente del edificio, anunciado como sede de la exposición en el cartel editado por la propia Diputación Provincial, en las fechas que este mismo cartel fijaba para su celebración.

Discute también la respuesta procesal de la Administración apelante la existencia de los perjuicios y su cuantía.

No parece necesario abundar en razones para estimar que el proyecto de exposición de la obra de un conocido pintor, anunciada públicamente, en un centro cultural de prestigio, que no se llega a consumar, con independencia de los costes materiales que haya tenido para el autor de la obra (a los que más adelante nos referiremos), supone un daño moral indemnizable atendiendo a las circunstancias del caso y al 
principio de equidad (Sentencia de la Sala Tercera -Sección Segunda- de este Tribunal, de fecha 4-4-1989, y de la misma Sala - Sección Tercera-, de fecha 31-10-1990). A la sazón, se produjo la frustración de una legítima aspiración del pintor de dar a conocer su obra y además el desmerecimiento que para la opinión pública constituye la ligereza y falta de seriedad del anuncio de la exposición, lo que justifica sobradamente la pretensión de la indemnización, por tal concepto, en la cantidad que el Tribunal a quo señaló como merecida en el cuarto de los Fundamentos de derecho de su Sentencia y que, probablemente por simple error material, se redujo en la parte dispositiva de aquélla.

Por lo que respecta a los gastos por montaje técnico, efectuados por el pintor con el fin de exhibir públicamente la obra (material de carpintería de enmarcado, transporte de marcos y material, cristalería y enmarcado), no sólo están justificados mediante facturas, cuya autenticidad (contrariamente a lo que ahora se afirma) no fue impugnada al contestar la demanda, sino que es razonable efectuarlos para ultimar la presentación de una obra pictórica al público, mientras que carece de lógica la insinuación de la representación procesal de la Administración demandada al decir que "pudieran no corresponder a gastos concretos relacionados con este asunto", porque tanto las fechas como los conceptos de dichas facturas son coherentes con la exposición de pintura anunciada en el cartel editado por la misma Diputación Provincial.

Finalmente, debemos examinar si procede indemnizar al demandante, según declaró la sentencia apelada, por el beneficio material dejado de percibir al no realizarse la exposición. El Tribunal a quo lo fija, siguiendo la pauta expuesta en el escrito de demanda, en un cinco por ciento del valor de las obras que habían de exhibirse conforme a la relación de cuadros y a la lista de precios presentadas por el propio autor. Hemos, sin embargo, de tener en cuenta el significado eminentemente cultural del proyecto, como se deduce del catálogo y del cartel anunciador, que relega a un plano muy secundario la posible ganancia que, al no celebrarse la exposición, constituiría el hipotético lucro cesante. De esta clase de muestras pueden, sin duda, derivarse ventajas económicas para el autor de la obra por la venta, pedido o encargo de alguna, pero no deja por ello de constituir una remota expectativa, que no es el fin de aquélla, y en consecuencia, como ganancias meramente posibles, pero inseguras, dudosas o contingentes, por estar desprovistas de certidumbre y carecer de prueba rigurosa, no es admisible su cómputo para fijar la indemnización reclamada, según ha declarado la Jurisprudencia de la Sala Tercera - Sección Tercera- de fecha de 20-2-1989. 
JURISPRUDENCIA

De lo dicho se deduce que hemos de estimar en parte el presente recurso interpuesto por la Diputación Provincial de Cáceres e íntegramente la pretensión formulada por el adherido a la apelación».

(Sentencia de 18 de octubre de 1993. Ar. 7.498. Peces Morate).

\section{BIENES}

1. Orden de paralización provisional de obras en terrenos incluidos en una concesión administrativa a perpetuidad para desecar marismas $y$ destinarlas a la acción urbanizadora. Transmutación de terrenos de dominio público en propiedad privada. Concurrencia de competencias en zona maritimo-terrestre entre la Administración del Estado y la Administración Local. Existencia de facultades de intervención de la Administración del Estado de vigilancia de las condiciones impuestas en la concesión sobre aspectos que no sean de la competencia urbanistica de otras Administraciones.

«Finalmente dice el señor Abogado del Estado que el carácter de la primitiva concesión, que se refería a destino de urbanización, no es obstáculo para el cumplimiento del resto del clausulado de la misma, con la necesaria intervención del Ministerio de Obras Públicas y Urbanismo. El señor Abogado del Estado se refiere, sin duda, a la cláusula $3 .^{2}$ de la Resolución de 31-10-1955, que impuso al concesionario la obligación de "dar cuenta a la jefatura de Obras Públicas de la provincia de la cesión de cada una de las parcelas, fijándose los términos en que la misma se hace así como su situación y nombre de la persona a quien se cede, para su aprobación previa por la superioridad, si procede". La Sentencia impugnada no se refiere a esta cláusula, y llega a la conclusión de que la Administración del Estado carece de facultades de intervención pues "declinó todo lo referente a los aspectos urbanísticos ulteriores a favor

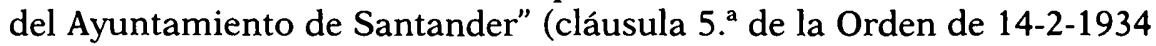
y apartado segundo de la de 31-10-1955). Y aquí es donde hemos de introducir las matizaciones apuntadas.

Ocurre que el control urbanístico no excluye otros posibles controles, pues pueden existir competencias concurrentes (art. 57.2 del Texto Refundido de la Ley del Suelo), y esto es tan evidente que no necesita mayor explicación - no otra cosa dice el Tribunal Constitucional en su S. núm. 149/1991, de 4 de julio, pues afirma la constitucionalidad de la atribución a la Administración del Estado de la facultad de vigilancia del cumplimiento de las condiciones impuestas en las concesiones y 
autorizaciones otorgadas por ella (punto $\mathrm{c}$ del núm. A del F. 7), siempre naturalmente que el control se realice sobre aspectos que no sean de la competencia de otras Administraciones, pues en otro caso (vgr. competencias urbanísticas) su control corresponde a éstas-. La Administración del Estado tiene, según el título en virtud del cual los terrenos pasaron del dominio público al privado, la facultad de aprobar las sucesivas cesiones, pero no (por lo menos en la actualidad) para hacer cumplir la legalidad urbanística, sino para otras finalidades muy simples, algunas explícitas (vgr. conservar en lo sucesivo los muros y rellenos que comprende el servicio público, tal como dice la cláusula 12 de la concesión primitiva) y otras implícitas (normales en concesiones de este tipo, como la de edificar con la rasante obligada e impedir que el agua entre en las parcelas; por cierto, condiciones impuestas expresamente en la concesión de que este Tribunal Supremo conoció en su citada S. 9-101992); todos estos aspectos no son estrictamente urbanísticos, sino atinentes a la salvaguarda de la finalidad originaria, que fue la de ganar terrenos al mar. Esta es una competencia que, aunque los terrenos sean privados - que lo son- sigue teniendo la Administración de Costas con independencia de la urbanística que corresponde a la Administración Local, y la tiene porque se la deriva del título originario. Ahora bien: en el presente caso nunca la Administración ha ni siquiera apuntado que las obras suspendidas puedan atentar al mantenimiento de los muros de cierre, ni que puedan violar la rasante obligada ni que puedan hacer peligrar la contención del agua marítima; como puede comprenderse (y este Tribunal lo deduce del puro examen de las fotografías que obran en el recurso) no se necesitan grandes estudios ni cálculos para deducir si las obras en cuestión conllevan o no esos peligros, así que si la Administración no ha dicho nada acerca de ellos, habrá que concluir que no existen y, por lo tanto, que ni siquiera desde este punto de vista resulta conforme a Derecho que se anunciara expediente sancionador y se suspendieran las obras.

Y si desde esa perspectiva material o de fondo, pasamos a la puramente formal que parece esgrimir en esta apelación el señor Abogado del Estado (a saber, que la infracción existe simplemente porque la entidad actora no sometió la concesión a la aprobación del Ministerio), entonces diremos lo siguiente: según hemos expuesto más arriba, al reservarse la Administración en las soluciones primitivas lo que con el tiempo ha llegado a ser una mínima intervención, pretendía evitar que se causasen daños en los muros de cierre, o que se edificase violando la rasante obligada, o que se corriera el riesgo de que el mar entrara de nuevo en las parcelas y, por lo tanto, sólo ese control (y no el general de ordenación del territorio ni el urbanístico), puede ejercer la Adminis- 
JURISPRUDENCIA

tración sobre unos terrenos que ni son de dominio público ni están afectados por las servidumbres del dominio marítimo. Para llevar a cabo ese control mínimo la Administración carece de potestad de suspender cautelarmente las obras, pues no le viene dada en la legislación de costas (que la regula con referencia a las que se realicen en terrenos de dominio publico) ni en las resoluciones originarias; podrá simplemente, y sólo cuando existan motivos racionales para creer que no se respetan los citados límites, requerir la presentación de títulos de transmisión o de proyectos de edificación o de obras, así como inspeccionar las mismas a tal fin, y podrá en efecto suspender las obras cuando, a la vista de todo ello, quede demostrado que se perjudican los muros de cierre o la rasante o la contención del mar. Y como nada de esto se ha demostrado (y ni siquiera alegado) en el supuesto de autos, la sentencia apelada es conforme a Derecho al anular los actos impugnados».

(Sentencia de 16 de julio de 1993. Ar. 6.202. Yagüe Gil).

2. Acuerdo municipal por el que se declara la reversión de terrenos cedidos para uso privativo y la caducidad de concesión administrativa de Bar situado en terrenos de parque público. Existencia de razones de interés general para la extinción de los derechos derivados de la concesión.

«El análisis de las alegaciones formuladas por las recurrentes en la presente alzada desvela que son dos los motivos principales o relevantes de impugnación que aduce la parte actora contra los actos del Ayuntamiento cuya anulación pretende, motivos que ya habían sido esgrimidos como fundamento de los sucesivos recursos de reposición en vía administrativa y contencioso-administrativa en primera instancia, habiendo sido rechazados en la Sentencia apelada; debe significarse que las aludidas alegaciones de la parte recurrente adolecen de algunas imprecisiones jurídicas e incoherencia interna, en algunos extremos concretos. Los repetidos motivos son, de un lado, el de naturaleza formal consistente en la supuesta concurrencia de causa de nulidad radical de los acuerdos municipales recurridos, por contravenir lo dispuesto en el art. 47.1 c), en relación con los arts. 88 a 90, 91 y 136 que se citan expresamente en la demanda, todos ellos de la Ley de Procedimiento Administrativo, en tanto en cuanto fueron dictados, a su juicio, en un expediente sancionador, lo cual supondría vicio de indefensión; de otra parte, que aun cuando la parte actora y ahora apelante admite expresamente la naturaleza del bien demanial del terreno situado en el parque público conocido como "La Arboleda", en el que se asientan las instalaciones 
del Bar que constituye el objeto material del litigio, mantiene que, dado el contenido obligacional de los convenios concertados por los causahabientes de las actoras y el Ayuntamiento demandado, las demandantes ostentan un derecho real de superficie asimilable al "censo enfitéutico" sobre las instalaciones o edificación construidos al amparo de la concesión municipal, con plena propiedad sobre el local y la industria asentados en aquéllos, cuya expropiación requeriría en todo caso la incoación de un expediente de esta naturaleza, resultando por ello improcedente el acuerdo municipal de reversión de los terrenos cedidos para uso privado, así como la caducidad decretada respecto de la concesión.

El primero de dichos motivos carece de toda consistencia fáctica y jurídica y debe ser rechazado como hace la Sentencia recurrida con base en consideraciones que no procede reproducir, bastando para ello con poner de relieve, de un lado, que la intervención de las actuales demandantes en el expediente administrativo, en el que formularon oportunamente recurso de reposición, así como la posibilidad de alegar y probar en este proceso cuanto han tenido por conveniente en defensa de sus pretendidos derechos, vedan la posibilidad de aceptar su invocada indefensión (la que de existir sería contraria al principio constitucional de tutela judicial efectiva que consagra el art. 24.1 de la Constitución), vicio de indefensión que en este caso no se ha dado, habida cuenta de la conocida y reiterada doctrina consagrada en numerosas y muy citadas Sentencias del Tribunal Constitucional y de este Tribunal Supremo que, por sobradamente conocidas, no es preciso aquí citar expresamente; y en cuanto a la existencia total del cauce procedimental administrativo adecuado, que la parte recurrente aduce con poca precisión, tanto respecto del que califica de procedimiento sancionador como del expropiatorio (lo cual no es ciertamente muy congruente) es suficiente para poner de relieve la falta de consistencia de esta alegación con remitirse a lo que seguidamente se argumenta, en relación con la naturaleza de la relación jurídica nacida de los convenios y concesión de uso que de ellos derivó y del alcance jurídico de los actos impugnados en este proceso.

La cuestión básica del presente litigio radica, por tanto, en determinar la naturaleza de la relación jurídica que une a las actoras con el Ayuntamiento demandado, en virtud de los referidos convenios y actos municipales, que, en su día, aprobaron los mismos. Pues bien, esta cuestión debe ser resuelta en el sentido que mantiene la Corporación demandada y, en lo esencial, acoge la Sentencia apelada; es decir, que se trata de una concesión administrativa otorgada a los causantes de las actua- 
les litigantes para la ocupación privativa de terrenos de dominio público municipal (art. 78.1 a) del citado Reglamento de Bienes), con la finalidad de instalar y explotar un negocio de bar, a cambio de un exiguo canon anual, y ello por tiempo indefinido, lo cual está ahora en abierta discordancia con lo dispuesto en el art. 79 del propio Reglamento.

En consecuencia, forzoso es concluir que el Ayuntamiento estaba facultado por los arts. 44. 1c), 120 y concordantes del citado Reglamento para acordar de oficio, por razones de interés general (destinarlo a zona verde) y de acuerdo además con lo expresamente pactado, la extinción de los derechos derivados de la expresada concesión o, lo que es sustancialmente lo mismo, a denunciar la misma o decretar la reversión del terreno (cosa distinta de la expropiación forzosa de un derecho real sobre el edificio del Bar "La Chabola", como aduce la parte apelante), sin más que abrir al mismo tiempo el cauce procedimental para lograr la efectividad de la ocupación municipal del inmueble y, al propio tiempo, establecer con audiencia de los titulares de la concesión la correspondiente indemnización por daños y perjuicios; y así lo hizo la Corporación Municipal en el Acuerdo impugnado de 30-12-1988, confirmado en reposición por el de 21-12-1989, los que revisten el carácter de actos de trámite en el procedimiento de fijación del importe de la indemnización, y no de naturaleza definitiva expropiatoria como parece mantener la parte apelante puesto que alega la inexistencia total de procedimiento como causa de nulidad absoluta».

(Sentencia de 5 de octubre de 1993. Ar. 7.351. Pastor López).

\section{EXPROPIACIÓN FORZOSA}

1. Indemnización por exclusión de finca del expediente expropiatorio. Beneficiario y concesionario de servicio público. Identidad de razones para exigir del beneficiario las responsabilidades explicitadas en la Ley de Expropiación Forzosa para el concesionario.

«El aquietamiento de la demandante (no comparecida en casación) evita examinar si es o no conforme a Derecho la decisión de la Sala de instancia al confirmar los acuerdos administrativos que excluyeron de la expropiación forzosa las fincas de su propiedad, de manera que el debate se circunscribe, exclusivamente, a determinar el obligado al pago de la indemnización, ya que la Administración autonómica, única recurrente en casación, no plantea la cuestión sobre la procedencia de la indemnización ni los criterios establecidos por la Sala de instancia en 
cuanto a las bases que han de servir para fijar aquella indemnización en ejecución de Sentencia.

Concretamente, los términos del debate se centran en la imputabilidad de la indemnización que debe pagarse a la titular de la finca excluida de la expropiación, es decir si es imputable a la beneficiaria, como sostiene la Administración expropiante, o lo es a ésta, como defiende aquélla con los mismos argumentos empleados en la Sentencia de instancia.

Las partes comparecidas en casación conocen la doctrina al respecto de este Tribunal, al haber sido partes también en el recurso de apelación que ante esta propia Sala y sección se siguió con el núm. 9.878/1990, en el que recayó Sentencia con fecha 11-10-1991, resolviendo un caso idéntico al que ahora se dirime.

No nos queda, pues, sino reiterar la doctrina, ya establecida, que considera aplicable, por analogía al beneficiario de la expropiación lo dispuesto por los arts. 121.1 y 123 de la Ley de Expropiación Forzosa respecto del concesionario de servicios públicos, al estimar que existe idéntica razón para determinar la responsabilidad del concesionario de un servicio público en sentido estricto que para declarar la del concesionario demanial del yacimiento minero, cuya titularidad le confiere precisamente el carácter de beneficiario de la expropiación, y como tal asume, en el procedimiento expropiatorio, un protagonismo material y jurídico de la misma naturaleza que el concesionario de servicios públicos, según se deduce de las facultades que atribuye a aquél el art. $5 .^{\circ}$ del Reglamento de Expropiación Forzosa, por lo que, ante tal identidad de situación jurídica, es procedente, en ausencia de norma expresa, aplicar el mismo régimen jurídico que para los concesionarios de servicios públicos previenen los citados artículos de la Ley de Expropiación Forzosa y que después hizo extensivo a los contratistas de obras públicas el art. 134 del Reglamento General de Contratación del Estado, aprobado por Decreto 3.410/1975, de 25 de noviembre. En consecuencia, la reparación de los daños y perjuicios causados a la titular de la finca excluida de la expropiación incumbe a la Empresa beneficiaria de la expropiación.

Ciertamente, como sostiene la representación procesal de la entidad recurrida, la potestad expropiatoria reside en las Administraciones públicas territoriales, pero cuando éstas la ejercen en beneficio de otra persona (arts. 2.2 de la Ley de Expropiación Forzosa y 3.1 de su Reglamento), ésta ejerce, por sustitución, funciones públicas a pesar de ser 
JURISPRUDENCLA

una persona jurídico privada, lo que repercute en las consecuencias que produce la actuación expropiatoria que promueve y de la que se beneficia, y de aquí que el art. 4 del Reglamento de la Ley de Expropiación Forzosa, aprobado por Decreto de 26-4-1957, al deslindar las atribuciones de la Administración expropiante y del beneficiario, disponga que corresponden a aquélla, en su calidad de titular de la potestad expropiatoria, "decidir ejecutoriamente en cuanto a la procedencia y extensión de las obligaciones del beneficiario respecto al expropiado", previsión normativa que supone identidad de razón para atribuir a la Administración la facultad y la obligación de resolver, en la forma establecida por el referido art. 123 de la Ley de Expropiación Forzosa para los servicios concedidos, cuando el expropiado reclama una indemnización por daños y perjuicios a cargo del beneficiario de la expropiación.

En contra de la opinión del Tribunal a quo, cuya tesis defiende la entidad beneficiaria de la expropiación, esta Sala y Sección, en su citada Sentencia de fecha 11-10-1991, declaró que el acto administrativo de exclusión de bienes, emanado de la Administración Autonómica, no incorpora en rigor, una determinación propia, sino una pura y simple aceptación formal, como titular del trámite expropiatorio de una actuación materialmente referible al beneficiario, como es la que le impone el artículo 17 de la Ley de Expropiación Forzosa, en relación con el artículo 15 de la misma, de formular la relación de los bienes o derechos que considere de necesaria ocupación, la cual, mediante la solicitud de exclusión de determinadas fincas, es modificada por el propio beneficiario, alterando el acuerdo de necesidad de ocupación, a la que la Administración tan sólo confiere carácter formalizado, realizando un acto estrictamente reglado dada la justificación de la exclusión, razones que, unidas a las anteriores, obligan a declarar la obligación de la Empresa Nacional de Electricidad, S. A. (ENDESA) de pagar, como beneficiaria de la expropiación, los daños y perjuicios sufridos por la propietaria de la finca excluida de aquélla, que se determinen en ejecución de Sentencia con arreglo a las bases fijadas por la Sentencia de instancia».

(Sentencia de 25 de octubre de 1993. Ar. 8.007. Peces Morate).

2. Derecho a la retasación. Consignación del justiprecio por la Administración expropiante. Litigio sobre la titularidad de la finca.

«Según lo dispuesto concordadamente por los arts. 3.2 de la Ley de Expropiación Forzosa y 6.1.7 y 19.3 del Reglamento de esta Ley, la Administración expropiante, salvo prueba en contrario, ha de conside- 
rar a quien con tal carácter conste en registros públicos que produzcan presunción de titularidad, que sólo puede ser destruida judicialmente, de manera que, para que, conforme al art. 7 de dicha Ley, se opere formalmente en el expediente expropiatorio la subrogación del adquiriente de un bien o derecho en curso de expropiación, deberá ponerse en conocimiento de la Administración el hecho de la transmisión y el nombre y domicilio del nuevo titular, siendo tomadas únicamente en consideración las transmisiones judiciales, las inter vivos que consten en documento público y las mortis causa respecto de los herederos o legatarios (art. 7 del Reglamento citado).

La Administración actuó de acuerdo con las normas transcritas, a pesar de que un tercero presentó el documento privado anteriormente referido, sin considerar, en ningún momento, la propiedad como litigiosa, pues, de estimarlo así, debería haber dado cumplimiento a lo establecido en el art. 5 de la misma Ley de Expropiación. No obstante, en lugar de pagar el justiprecio a los que como tales propietarios había tenido durante todo el procedimiento expropiatorio, deposita su importe en la Caja General de Depósitos sin justificación alguna y sin previamente haberles ofrecido dicho pago. A posteriori, al resolver la reclamación formulada por la ahora apelante ante el silencio de la Administración sobre su petición de retasación, el Consejero de Política Territorial de la Comunidad de Madrid deniega tal pretensión porque los interesados en el expediente no habían promovido procedimiento alguno por el que se declare, de modo indubitado, la titularidad del inmueble objeto del expediente, a la vista de aquel contrato privado tantas veces citado.

Los titulares registrales de la finca expropiada o sus causahabientes, por el hecho de haberse presentado en el expediente administrativo un documento privado, en el que consta un pacto de venta (no susceptible por sí solo de transmitir el dominio, ya que éste se adquiere por consecuencia de ciertos contratos mediante la tradición - título y modosegún el art. 609 del Código Civil), no están obligados a promover, contrariamente a lo expresado en el acto administrativo impugnado, proceso judicial alguno para obtener una declaración de propiedad a su favor, ya que, conforme a los preceptos transcritos de la Ley de Expropiación Forzosa y su Reglamento, la Administración ha de considerar propietarios del bien expropiado a quienes como tales aparecen en el Registro de la Propiedad, ya que éste conforme al art. 38 de la Ley Hipotecaria, produce la presunción de titularidad dominical a que se refiere el citado art. 3.2 de la propia Ley de Expropiación Forzosa, sin que la Administración pueda tomar en consideración, según el también refe- 
JURISPRUDENCIA

rido art. 7 del Reglamento de esta Ley, otras transmisiones que las judiciales, las inter vivos que consten en documento público y las mortis causa respecto de los herederos o legatarios, sin que pueda excusarse de pagar a los propietarios registrales, tenidos como interesados a lo largo del expediente expropiatorio, en lo dispuesto por los arts. 8.2 y $51.1 \mathrm{~b}$ ) del Reglamento de la Ley de Expropiación por el hecho de haberse presentado un documento privado en el que conste que uno de los titulares del dominio vende la finca a un tercero, ya que no es éste el supuesto contemplado por estos preceptos del Reglamento citado, ni en que la propiedad es litigiosa porque no existe litigio alguno.

El art. 8.2 del Reglamento de la Ley de Expropiación Forzosa, aducido por la Sentencia apelada como justificación de la consignación del precio llevada a cabo por la Administración, se refiere al desacuerdo en la distribución del justiprecio entre distintos titulares de derechos, eventualidad que no se da porque entre los propietarios de la finca expropiada no hubo tal desavenencia. Tampoco se está ante el caso contemplado por el art. 51.1 b) del mismo Reglamento, porque los únicos interesados, según hemos dicho anteriormente, eran los titulares registrales, ya que, como establece el art. 19.3 del Reglamento de la Ley de Expropiación Forzosa, la condición de interesado sólo se reconocerá a las personas definidas en los artículos (ya citados) 3 y 4 de la Ley y 6 y 7 del Reglamento.

Es cierto que el art. 3.2 de la Ley de Expropiación Forzosa deja a salvo la prueba en contra de la presunción de titularidad que el propio precepto establece, pero, como hemos expuesto, un documento privado que contiene un pacto de venta no tiene eficacia para destruir la presunción de titularidad dominical en favor de quien aparece como propietario en el Registro de la Propiedad porque (según hemos dicho también), aun aceptando la validez del documento en cuestión, el contrato de compraventa por sí solo, salvo que se haga mediante escritura pública (art. 1.462, párrafo segundo, del Código Civil), carece de eficacia para transmitir el dominio al faltar el modo o toma de posesión del comprador (art. 609 del propio Código Civil).

Sólo en el caso de que un tercero acreditase haber promovido litigio ante los Tribunales competentes sobre la titularidad de la finca en cuestión frente al titular o titulares inscritos, reconocidos por la Administración como interesados en el expediente expropiatorio, debería ésta consignar la cantidad a que asciende el justo precio, como establece el art. 51.1 b) del Reglamento de la Ley de Expropiación Forzosa, quedando liberada de la obligación de pagar el precio, al consignarlo en la 
Caja General de Depósitos, por resultar la propiedad litigiosa y pretender varios tener derecho a cobrar. Al no ser éste el supuesto contemplado, ya que no hay constancia de que el tercero que presentó el documento privado hubiese incoado pleito alguno ante los Tribunales, exigiendo el cumplimiento del contrato de compraventa, o ejercitando acción declarativa de dominio sobre la finca expropiada, la Administración no puede excusar el pago a quienes tuvo justamente como interesados en el expediente so pretexto de que no "han promovido procedimiento alguno por el que se declare, de modo indubitativo, la titularidad del inmueble objeto del expediente".

Al no existir litigio o cuestión alguna entre los interesados, ni entre éstos y la Administración, ni tampoco pleito pendiente entre los interesados y un tercero sobre la titularidad dominical de la finca expropiada, sólo cabría considerar como válida la consignación si, ofrecido el pago del precio a los interesados (arts. 1.176 del Código Civil y 50.1 de la Ley de Expropiación Forzosa), éstos no hubiesen concurrido al acto de pago o lo hubiesen rehusado. Al no haber habido previo ofrecimiento de dicho pago, la consignación por sí sola no libera a la Administración, que tampoco observó, según se desprende del expediente administrativo, la obligación de hacer saber la consignación acordada a las personas interesadas en el cumplimiento de la obligación, de manera que, según lo dispuesto por el art. 1.177 del Código Civil y las normas generales sobre eficacia de los actos administrativos contenidos en los arts. 45.2 y 79.1 de la Ley de Procedimiento Administrativo de 17-7-1958 (vigente al tiempo de aquélla), dicha consignación carece de eficacia liberatoria para la Administración.

En consecuencia, al haber transcurrido más de dos años sin que el pago de la cantidad fijada como justo precio se hubiese hecho efectivo o se consignase válidamente, debe procederse, en cumplimiento de lo dispuesto por el art. 58 de la Ley de Expropiación Forzosa, a evaluar de nuevo la finca expropiada, con arreglo a los preceptos contenidos en el capítulo III del título II de la Ley de Expropiación Forzosa, estimando así el recurso de apelación interpuesto contra la Sentencia pronunciada por el Tribunal de la primera instancia y el recurso contencioso-administrativo deducido en su día contra la Resolución, de fecha 10-12-1987, del Consejero de Política Territorial de la finca expropiada por "COPLACO", señalada con el núm. 20 del Proyecto de Urbanización del Sector Capitán Haya y Medina Sabuco, de Madrid".

(Sentencia de 13 de octubre de 1993. Ar. 7.495. Peces Morate). 
JURISPRUDENCIA

\section{URBANISMO}

1. Acuerdo de la Corporación Metropolitana de Barcelona sobre aprobación definitiva del Plan Especial de equipamiento alimentario. Constitucionalidad de la normativa reguladora de la Corporación Metropolitana. Ausencia de colisión con las competencias de la Comunidad Autónoma de Cataluña en materia de comercio interior respecto a la regulación de usos alimentarios por una entidad local.

«Al amparo de lo establecido en los arts. 65 y 66 de la Ley 7/1985, 2 abril, Reguladora de las Bases del Régimen Local, la Generalidad de Cataluña cuestiona la legalidad del Acuerdo adoptado por el Consejo Metropolitano de la Corporación Metropolitana de Barcelona, en 244-1986 (publicado en el Boletín Oficial de la Provincia de 31-5-1986), en cuya virtud se aprobó definitivamente el Plan Especial del Equipamiento Comercial Alimentario de Barcelona, interesando en la demanda articulada que, con estimación del recurso, se declare que dicho acuerdo excede de las competencias del ente demandado, que corresponden a la Generalidad de Cataluña, por lo cual es nulo de pleno derecho, y, en todo caso, que se declare que es contrario al Ordenamiento Jurídico, decretando, consecuentemente, la nulidad de dicho acuerdo. Tanto la Corporación demandada como el Ayuntamiento de Barcelona, codemandado, postulan la desestimación del recurso, con base en los argumentos que, al igual que los aducidos por la actora, después se ponderarán, en función de la normativa pertinente.

La tesis en que la recurrente funda su pretensión anulatoria, puede resumirse así: A) Buena parte de la legislación por la que se rige la Corporación Metropolitana de Barcelona, está afectada de inconstitucionalidad sobrevenida, por chocar frontalmente con la Constitución y el Estatuto de Autonomía de Cataluña, luego debe entenderse derogada o, al menos, ha de examinarse con la mayor reserva, sin que el tema se altere sustancialmente por lo dispuesto en la Disposición Adicional sexta de la Ley 7/1985, de 2 de abril, por lo que, de otro lado, habría de plantear el Tribunal la oportuna cuestión de inconstitucionalidad; B) El plan impugnado es contrario a los principios de libertad de empresa y libre competencia; C) Invade la competencia de la Generalidad en materia de comercio interior; D) Vulnera el art. 3 del Decreto Ley 6/1974, de 27 de noviembre; E) Es contrario a las previsiones de la Ley del Suelo y Reglamentos que la desarrollan; F) Infringe las disposiciones en que, según el Plan recurrido, se fundamenta el mismo. 
La decisión de la litis deriva de lo siguiente: $\left.1 .{ }^{\circ}\right)$ No cabe duda que el marco jurídico que informa el momento en que se dictó el acto ahora recurrido no coincide con el existente cuando se creó la Corporación Metropolitana de Barcelona (24-8-1974), pero este dato, por sí solo, carece de entidad bastante para entender derogado sin más el Decreto Ley 5/1974, de 24 de agosto, que creó la Corporación Metropolitana de Barcelona, pues para ello habría de apreciarse una clara colisión normativa entre dicho Decreto Ley, de un lado, y la Constitución de 1978, el Estatuto de Autonomía de Cataluña y todo el bloque normativo emanado de estas normas básicas, y, ciertamente, no se aprecia dicha contradicción, por lo siguiente: A) La propia Constitución, en su art. 141.3, establece que "se podrán crear agrupaciones de municipios diferentes de la provincia", luego el cuestionado Decreto Ley en cuanto crea la Corporación Metropolitana de Barcelona en modo alguno es contrario a la Constitución; B) El art. 5 del Estatuto de Autonomía de Cataluña prevé la posibilidad de crear agrupaciones basadas en hechos urbanísticos y metropolitanos y otras de carácter funcional y fines específicos, con lo que se llega a la misma conclusión antes dicha; C) La Disposición Adicional Sexta apartado segundo de la Ley 7/1985, de 2 de abril, reguladora de las Bases del Régimen Local, expresamente declara la vigencia de la normativa básica sobre constitución y desarrollo de la Corporación Metropolitana de Barcelona, así como de sus disposiciones concordantes, salvo, naturalmente, en lo que se oponga, contradiga o resulte incompatible con lo establecido en dicha Ley de Bases; luego también desde este aspecto carece de cobertura jurídica la pretensión del recurrente; y D) No existe fundamento razonable para que el Tribunal plantee la cuestión de inconstitucionalidad aludida por la actora, pues, como queda dicho antes, la normativa reguladora de la Corporación Metropolitana, en lo que respecta a los aspectos que interesan en esta litis, no aparece contraria a la Constitución. Por ello y sin perjuicio de que determinados aspectos sean incompatibles con el Texto Fundamental y, por ende, habrá que estimarlos derogados por la Constitución, dado el tenor de su Disposición Derogatoria Tercera, es lo cierto que en lo que atañe al punto aquí cuestionado, no cabe estimar se haya producido esa pérdida de vigencia; $2^{\circ}$ ) Aparte y además de que el reconocimiento que se hace en el art. 38 de la Constitución, de la libertad de empresa en el marco de la economía de mercado, ha de armonizarse con lo establecido en la propia Constitución (arts. 128 a 136), especialmente en su art. 131, es lo cierto que el mismo art. 38 , al señalar dicho reconocimiento del sistema de economía de mercado, se matiza en el sentido de que ello se hará "de acuerdo con las exigencias de la economía general y, en su caso, de la planificación"; por tanto, la tesis de la recurrente en este punto no puede prosperar, máxime si se tiene en cuenta que la regulación combatida atiende a los aspectos urbanísticos del tema y no a lo que es propiamente la activi- 
JURISPRUDENCIA

dad económica, en sí misma considerada; $3 .^{\circ}$ ) No se cuestiona aquí la competencia de la Generalidad sobre comercio interior, en los términos de lo establecido en el art. 12.5 del Estatuto de Autonomía, pero es que el Plan Especial que se impugna, como se indica en el art. 1 de su normativa, tiene por objeto, no regular el comercio interior de la ciudad de Barcelona, sino la regulación urbanística y la ordenación de los usos y de las actividades comerciales alimentarias en el término municipal de Barcelona, lo que entra en el ámbito competencial propio de la Corporación Metropolitana, como ente local, según se infiere, además del amplio campo que a la actividad urbanística se señala en el art. 3 de la Ley del Suelo; $4 .^{\circ}$ ) Las limitaciones contenidas en el Plan recurrido, no se basan en razones comerciales sino, en armonía con la finalidad del Plan, están en función de los usos del suelo, que es lo propio de la normativa urbanística; $5^{\circ}$ ) Sentado que el objetivo del Plan es netamente urbanístico, con la amplia gama que a este concepto se establece en el art. 3 de la Ley del Suelo, ha de señalarse que la figura del Plan Especial es idónea a los fines perseguidos, dado el tenor de los arts. 7, 23, y concordantes de la Ley del Suelo, que configuran tales Planes con extraordinaria amplitud, sin más limitaciones que las de no contrariar al Plan General, ni sustituirlo como instrumento de ordenación integral del territorio, sin que conste que, en el caso que nos ocupa, se hayan rebasado tales limitaciones, ni, por supuesto, las derivadas del art. 17 de las Normas Urbanísticas del Plan General Metropolitano, y 6.) Finalmente, y aunque sea irrelevante el mayor o menor acierto de la invocación que se hace en el art. 1 de la normativa del Plan impugnado, para explicar las bases jurídico-urbanísticas que en el mismo se desarrollan, es lo cierto que tales normas invocadas, al menos no contradicen el objetivo del Plan Especial, antes al contrario, presentan suficiente conexión con el mismo, según se advierte de la mera lectura de los preceptos que se citan. Por todo lo expuesto no puede prosperar el recurso ni la demanda articulada».

(Sentencia de 28 de septiembre de 1993. Ar. 6.630. Esteban Alamo).

2. Licencias municipales. Condicionamiento de la licencia a la ejecución simultánea de obras de urbanización. Ejecución subsidiaria de la Administración. Tales obras no pueden ser objeto de contribuciones especiales.

\section{FUNDAMENTOS DE DERECHO}

(Sentencia apelada)

«Se debate en este litigio la conformidad a Derecho de la Resolución del Ayuntamiento de Santander de 18-4-1990 que confirma en reposi- 
ción la anterior de 2-3-1990, relativa a las condiciones exigidas para conceder licencia de primera utilización de un edificio de viviendas en Cueto (Expediente 276 bis/83).

La indudable habilidad del recurrente, junto con el uso estereotipado de impresos con pie de recursos sin modificar ha propiciado la interposición (y consiguiente resolución) de no menos de cinco recursos de reposición contra el acto originario que nos ocupa, y ello pese a la prohibición expresa que contiene el art. 126.3 de la Ley de Procedimiento Administrativo ("contra la resolución de un recurso de reposición no puede interponerse de nuevo dicho recurso"). Se ha demorado de este modo, en contra de las exigencias elementales del principio de eficacia, la ejecución de un acto que hace años hubiera debido considerarse definitivo en vía administrativa, y de no ser por la afortunada intervención del funcionario técnico informante al folio 77 pudiera haber continuado su curso ininterrumpido de recurso tras recurso hasta la próxima década.

En realidad, pese a su aparente complejidad, la solución del litigio no puede ser más simple. El promotor de la edificación, obligado a realizar determinadas obras de urbanización por virtud de la Ley del Suelo (art. 83) y concretamente en virtud de la licencia de construcción del edificio, que se otorgó con el núm. 276 el 6-3-1984, bajo esa expresa condición (cláusula quinta del Acuerdo Municipal) entonces admitidas sin reservas, simplemente se ha aprovechado de los efectos favorables de la licencia y no ha realizado las obras a que se comprometió. El Ayuntamiento ha de acometerlas subsidiariamente y el promotor se niega ahora a sufragar su importe, con la "singular" tesis de que éste ha de ser repartido entre otros propietarios, que es la pretensión inserta en el suplico de la demanda.

Tal tesis es insostenible. Cuando la parcela a edificar no tenía, como es el caso, la calificación de solar, precisamente y entre otros motivos por falta de infraestructura viaria, no se puede otorgar licencia de edificación "salvo que se asegure la ejecución simultánea de la urbanización y edificación", debiendo el propietario del suelo (no los posteriores titulares de las viviendas que sobre él se edifiquen ni propietarios de otros suelos) "costear la urbanización": una elemental lectura del art. 83 de la Ley del Suelo así lo pone de relieve. Y precisamente en aplicación de esta norma se condicionó la licencia dada el 6-3-1984 admitiendo el señor $H$. que quedaba obligado a "la ejecución de las obras de urbanización... que se ajustarán al proyecto de 22-7-1983, ejecutándose previamente a las de edificación". Tales obras, pues, no pueden ser objeto 
JURISPRUDENCLA

de contribuciones especiales a repartir entre los vecinos sino que deben ejecutarse y sufragarse precisamente por el promotor de la edificación.

Sentado lo anterior, todo el curso del dilatado expediente no es sino muestra de la resistencia del recurrente a cumplir con sus obligaciones, esgrimiendo (con indudable éxito retardatorio) unos motivos u otros e introduciendo confusión en lo que está claro desde un comienzo. Se citan ahora en la demanda, como argumentos de impugnación: a) la falta de motivación del acto; b) la desviación de poder y la discriminación respecto de otros propietarios; c) la falta de proporcionalidad entre costes y propietarios afectados; d) la incidencia de las contribuciones especiales.

\section{FUNDAMENTOS DE DERECHO (Tribunal Supremo)}

Los de la Sentencia apelada, que se aceptan y además:

El apelante don Alejandro H. L., aceptando en la primera de sus alegaciones el acotamiento de los motivos impugnatorios hechos por la Sala de instancia en el quinto de los fundamentos de derecho de la Sentencia pronunciada por la misma, trata en las cuatro siguientes de desvirtuar los razonamientos que condujeron a su rechazo por ella, mas sin exponer otros con la suficiente prueba para contradecirlos, razón por la que su apelación ha de ser desestimada y la expresada Sentencia confirmada. En efecto, en lo que respecta a la falta de motivación del acto en forma alguna puede sostenerse tal falta cuando el Ayuntamiento de Santander, por la irregularidad producida por la serie de recursos de reposición interpuestos por el actor, dio a conocer, al menos en tres ocasiones, las razones que había tenido en cuenta para dictar el originario, pues una cosa es que un acto carezca de motivación, es decir, de la exteriorización y puesta en conocimiento del administrado de los motivos internos que condujeron a la formación de la voluntad, y otra muy distinta el que esos motivos no sean los susceptibles de formar válidamente la decisión adoptada, siendo la ausencia de aquélla y no la insuficiencia de éstos, lo que determina la nulidad prevista en el art. 48.1 de la Ley de Procedimiento Administrativo en relación con el art. 43.1 de la misma Ley. En lo que se refiere a la desviación de poder y discriminación respecto de otros propietarios, el recurrente está mezclando dos vicios distintos sin que se sepa en realidad si el segundo lo esgrime como supuesto del primero o si ambos los alega independientemente, mas sin que en uno u otro caso sea su impugnación atendible, toda vez, por una 
parte, que la discriminación no supone "el ejercicio de potestades administrativas para fines distintos de los fijados por el Ordenamiento Jurídico" que es lo que caracteriza la desviación de poder según la acertada definición del art. 83.3 de la Ley Reguladora de la Jurisdicción Contencioso-Administrativa, ya que el acto discriminatorio puede perfectamente ser válido para quien es discriminado aunque no se haya dictado otro igual para otras personas $\mathrm{y}$, por otra parte, colocándose ante la independencia alegatoria, la desviación de poder queda falta de soporte y la supuesta discriminación resulta inatendible a no ser predicable la igualdad más que ante situaciones dentro de la legalidad, de suerte que no puede pretenderse un trato igual y, por tanto, no discriminatorio, cuando al sujeto puesto en comparación se le ha tratado ilegalmente. En lo que atañe a la falta de proporcionalidad entre costes y propietarios afectados, motivo que se basa en el artículo 58 del Reglamento de Gestión Urbanística, encontrándonos ante una situación de aplicación de lo dispuesto en los arts. 83.1 del texto refundido de la Ley sobre Régimen del Suelo y Ordenación Urbana y 40 de dicho Reglamento, y no ante una actuación urbanística, supuesto a que se contrae aquel artículo, en la que tanto el actor como otros constructores estaban obligados a urbanizar y en la que el Ayuntamiento, después de hacer él las obras y aplicar contribuciones especiales, percatado de su error, exigió a los afectados tanto su importe como la parte a asumir por él, o sea, la totalidad del valor de las obras, es clara su falta de concurrencia, al producir el sistema de contribuciones especiales, por su propia naturaleza, la más perfecta ecuación entre costes y propietarios afectados. Y, finalmente, en cuanto a la incidencia de las contribuciones especiales, basta para descartar el vicio, nada menos que de nulidad radical del art. 47 de la Ley de Procedimiento Administrativo, que se le atribuye, la simple circunstancia de ya no pretender el Ayuntamiento percibirlas, con lo que no se da el supuesto de doble pago de las obras».

(Sentencia de 25 de octubre de 1993. Ar. 7900. Barrio Iglesias). 